\title{
Extracting Land Cover Change Information by using Raster Image and Vector Data Synergy Processing Methods
}

\author{
Tao Cheng ${ }^{1,2, a^{*}}$, Zhihong Gao ${ }^{1, b}$, Guangyong $\mathrm{Li}^{1, \mathrm{c}}$, Xinyan Zheng ${ }^{1, \mathrm{~d}}$, Jing \\ Yang $^{1, \mathrm{e}}$ \\ ${ }^{1}$ National Geomatics Center of China, China
}

${ }^{2}$ Key Laboratory for National Geographic Census and Monitoring, National Administration of Surveying, Mapping and Geoinformation, Wuhan, Hubei Province, China

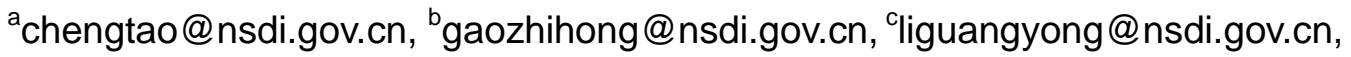

dzhengxinyan@nsdi.gov.cn, èyangjing@nsdi.gov.cn

Keywords: land cover; change detection; raster image; vector data; spatial overlap analyzing

\begin{abstract}
To enable the extracting of change information based on high spatial resolution images in a practicable and efficient mode, a method is developed and proposed by using raster image and vector data synergy processing. In the model designing of change detection indicator, it takes into account remote sensing indexes which have been processed by radiometric stretching. On the basis of these researches, it selects a test region and obtains the change information by utilizing the proposed method, change areas and change classes are captured by statistical calculating and spatial overlap analyzing respectively, which have validated the method's feasibility. The results verify that national land cover database is a good baseline for capturing high precision land cover change information by using raster image and vector data synergy processing method, which explores efficient mode and has the potential to provide practicable method for land cover change extracting for the project of Geographic National Conditions Monitoring.
\end{abstract}

\section{Introduction}

Study on land cover change has always been the forefront and hot issue in global change researches. Remote sensing technology has become one of the most economic and effective means for extracting and cover change information (Li 2013; Mei 2009; Rogan 2004). The Chinese Government has launched a project of Geographic National Conditions Monitoring. This project consists of two stages of geography census and geography monitoring; one of the most important missions is to grasp the status of national land cover comprehensively, and further to monitor land cover change caused by natural behaviours and human social economic activities by using professional technology of remote sensing, GIS, and so on (Chen 2012).

At present, two categories of land cover change information extraction methods based on remote sensing images are developing very well, which are pixel-based method and object-oriented method. Besides, the pixel-based method can be divided into two further categories: post classification comparison method and spectral difference method (Lu 2004).

Academician Deren Li of Chinese Academy of Sciences has systematically defined the concept for each method, and compared the differences between them. Particularly, he has described 7 methods' algorithm and data processing flow in detail (Li 2003). Xinfang Yu et al. have carried out comparison and analysis of the two category methods, and token an Inner Mongolia grassland area for example; the conclusion is that object-oriented method exhibits obvious superiority on overall accuracy and Kappa coefficient (Yu 2014).

Within these methods, the spectral difference method can determine the change areas of land cover change occurs, narrow the scope of classification, and improve the detection efficiency, but it cannot obtain the classes of land cover change (Zhang 2005). The post classification comparison method can determine the classes of land cover change, but the accuracy depends on the classification accuracy of multi-temporal images. The object-oriented method is not yet mature at present, and has not been widely used in engineering projects.

On the basis of abundant and superior background data, a land cover change information extraction method by using raster image and vector data synergy processing is proposed to meet the demands for change detection. 


\section{Methodology}

In the areas where land cover change occurs, the features on remote sensing image will change compared to the background data. So change areas can be extracted firstly by contrasting and analysing spectral difference of image whose temporal is different from background data; and the results could be saved as vector polygons. Then, change classes can be extracted by spatial overlap analysis between change vectors and background data of land cover. On the basis of these processing, proposed method can extract change information entirely, so as to grasp the status and change information of land cover.

The proposed method requires image pre-processing, remote sensing index calculation, change detection indicator design, change areas and change classes determination.

\section{Image pre-processing}

1) Image ortho-rectification

Ortho-rectification is necessary for processing images acquired in different temporal. Classical digital differential rectification algorithms, such as col-linearity equations, Rational Function Model (RFM), Rational Polynomial Coefficient model (RPC), etc. can be selected for this processing, according to different image sources.

2) Radiometric quantization unifying

The radiometric quantization bit number is related to radiometric resolution, such as WorldView-2 image's bit number is 16. When this bit number of image is different from background data, radiometric quantization unifying is needed to ensure change detection indicator calculation for each factor on the same scale and same magnitude.

\section{Remote sensing index calculation}

Classical remote sensing indexes, such as NDVI, Normalized Difference Water Index (NDWI), are both processed for normalizing, and the normalized range is from -1.0 to 1.0, so the difference between same indexes is also in a small numerical range.

But small value of remote sensing index difference may represent larger change information; therefore, the following transformation and calculation must be performed for remote sensing index difference.

1) Positive converting for index difference

Negative remote sensing index difference should be stretched to non-negative range. In the design of change detection indicator, positive numerical value should be used for representing change magnitude.

2) Quantization range stretching

The spectral difference between different temporal image and background data at the same pixel is related to radiometric quantization bit number and color saturation; besides, the value of remote sensing index difference is not on the same quantitative level with it. Therefore, quantization range of remote sensing index difference value must be stretched.

\section{Change detection indicator design}

Proposed method selects classical Euclidean distance as indicator of change detection, and carries on improvement, adds remote sensing index factors in it, the formula is as follows:

$$
d_{i}=\sqrt{\sum_{p=1}^{n}\left(x_{t 1}-x_{t 2}\right)^{2}}
$$

where $d_{i}$ is indicator value of pixel $i ; x_{t 1}, x_{t 2}$ are the digital number of band $p$ in the images of temporal $t 1, t 2$ respectively; $n$ is the band number.

\section{Change areas and change classes determination}

Threshold is needed to determine whether the pixel change or unchanged after complete calculating of change detection indicator (Rosin 2002, 2003), which can capture the suspicious change pixels. Generally, weighted average and standard deviation values are used in classical algorithm to definition the threshold calculation formula as following, on the basis of histogram statistics of change detection indicator value (Xian 2009).

$$
c=\bar{d}+a_{i} \sigma_{i}
$$

where $c$ is the threshold; $\bar{d}$ and $\sigma_{i}$ are the weighted average and standard deviation values of change detection indicator; $a_{i}$ is adjusting parameter, from 0.0 to1.5 (Morisette 2000). 
Pixel whose change detection indicator value is greater than or equal to the threshold is suspicious change pixel; oppositely, it is unchanged pixel.

\section{Experiment and result analysis}

The study area covers a region of 8.0 square kilometres, which belongs to flat terrain, and elevation range is from 0 to 95.0 meters. Various classes of land cover, such as cultivated land, forest land, grassland, water, building construction, road, etc. are included in this area.

Pair of RapidEye scenes covering study area is used for change detection, which has 5 bands of blue, green, red, red -edge, and near infrared, and the spatial resolution is 6.5 meters. In order to reduce the impacts of seasonal variation, the pair of scenes is selected in nearly the same seasons, which are 12/24/2011 and 11/6/2012 as shown in Figure 1 and Figure 2. The images' quality is good, and there is no cloud covering.

\section{Data processing}

Land cover classification was carried on the scene of 12/24/2011 according to the land cover classification system determined in the project of Geographic National Conditions Monitoring, which formed the background data of land cover.

The land cover classification system defines 10 classes of Level I, which are cultivated land, garden plot, forest land, grassland, building construction, road, structure, artificial stack land, bare land and water; also it defines 102 classes of Level III. As guided, 9 classes of Level I and 20 classes of Level III were classified in study area. The classification result is shown in Figure 3, statistics areas of classes of Level I are shown in Table 1.
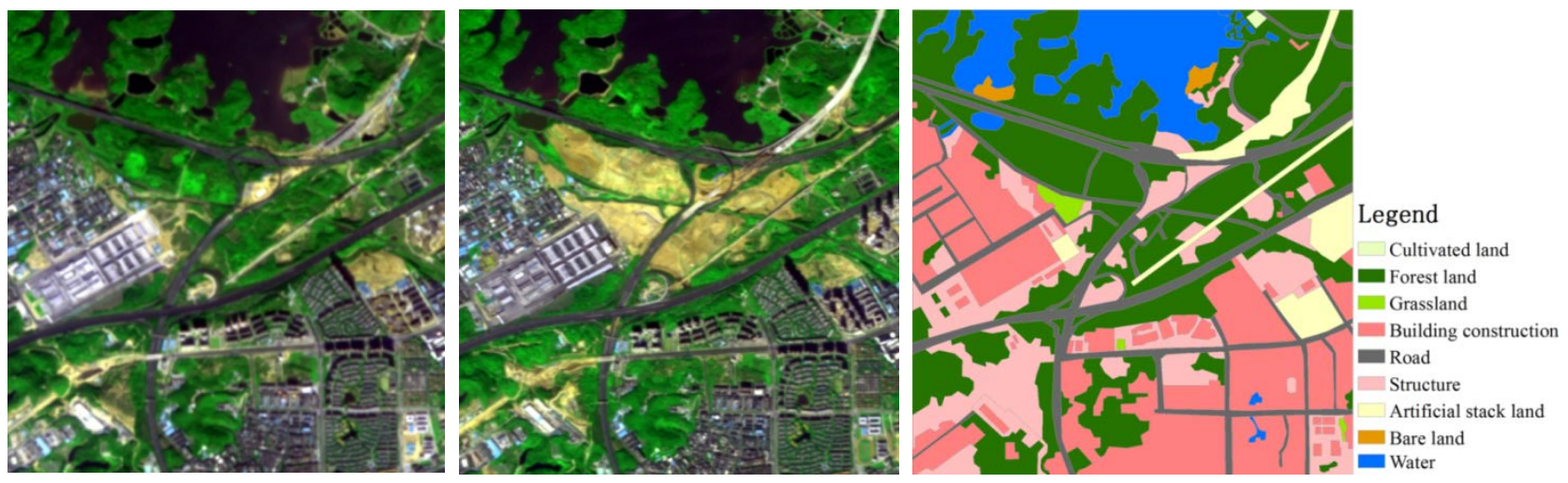

Figure 1. Image of 12/24/2011

Figure 2. Image of 11/6/2012 Figure 3. Land cover classification result for image of 12/24/2011

Table 1. Area statistics of land cover for each class (unit: $\mathrm{m}^{2}$ )

\begin{tabular}{|c|cc|}
\hline Order number & Class & Area $\left(\mathrm{m}^{2}\right)$ \\
\hline 1 & cultivated land & 7503.4 \\
2 & forest land & 2780149.7 \\
3 & grassland & 38964.7 \\
4 & building construction & 1897208.7 \\
5 & road & 924175.1 \\
6 & structure & 1158743.2 \\
7 & artificial stack land & 398397.3 \\
8 & bare land & 42070.4 \\
9 & water & 744035.0 \\
Total & & 7991247.5 \\
\hline
\end{tabular}

\section{Result and analysis}

Change detection indicator values of all pixels were calculated by using formula (1), and then the change magnitude map and its statistical histogram could be created as shown in Figure 4 and Figure 5. Based on the statistical histogram, weighted average and standard deviation values were obtained, which were 370.5 and 345.6 respectively. The adjusting parameter was set as 1.1 , so the calculating threshold value was 750.7. Then, the suspicious pixels were extracted as shown in Figure 6; the white regions were change areas where land cover change occurred. 

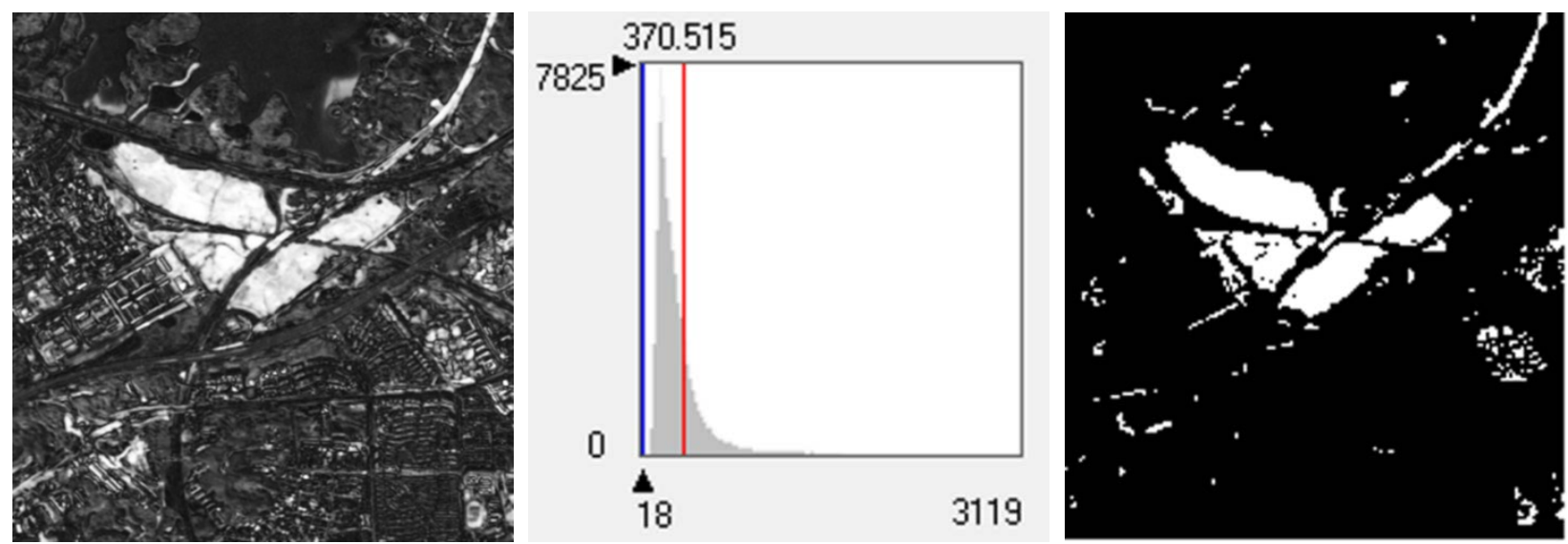

Figure 4. Change magnitude map Figure 5. Statistical histogram of change magnitude map Figure 6. Result of land cover change information extraction

To capture change classes, spatial overlap analyzing was performed between change vector and background data of land cover, including vector polygons' overlay (Chen 2010), intersection, identity. Besides, noise was removed during the processing (Tiwari 2011). The results of change and statistical information are shown in Table 2.

Table 2. Area statistics of land cover change for each class (unit: $\mathrm{m}^{2}$ )

\begin{tabular}{|c|c|c|c|c|c|c|c|c|c|c|}
\hline${ }_{\text {Class }}{ }^{\text {Class }}$ & $\begin{array}{l}\text { cultivate } \\
\text { d land }\end{array}$ & forest land & grassland & $\begin{array}{c}\text { building } \\
\text { construction }\end{array}$ & road & structure & $\begin{array}{c}\text { artificial } \\
\text { stack land }\end{array}$ & $\begin{array}{l}\text { bare } \\
\text { land }\end{array}$ & water & total \\
\hline cultivated land & 0 & 0 & 0 & 0 & 0 & 0 & 0 & 0 & 0 & 0 \\
\hline forest land & 0 & 0 & 0 & 2201.5 & 806.4 & 449903.7 & 0 & 5146.7 & 1359.5 & 459417.8 \\
\hline grassland & 0 & 0 & 0 & 0 & 0 & 15733.2 & 0 & 0 & 0 & 15733.2 \\
\hline $\begin{array}{c}\text { building } \\
\text { construction }\end{array}$ & 0 & 452.8 & 0 & 3131.0 & 0 & 7607.7 & 0 & 0 & 0 & 11191.5 \\
\hline road & 0 & 0 & 0 & 4245.4 & 0 & 31859.4 & 0 & 0 & 0 & 36104.8 \\
\hline structure & 0 & 1637.7 & 2206.2 & 19422.7 & 8012.4 & 0 & 0 & 0 & 0 & 31279.0 \\
\hline $\begin{array}{c}\text { artificial stack } \\
\text { land }\end{array}$ & 0 & 0 & 2997.9 & 41979.8 & 42578.7 & 2894.8 & 0 & 395.9 & 0 & 90847.1 \\
\hline bare land & 0 & 0 & 0 & 0 & 0 & 0 & 0 & 0 & 7916.8 & 7916.8 \\
\hline water & 0 & 0 & 0 & 0 & 0 & 0 & 0 & 0 & 0 & 0 \\
\hline total & 0 & 2090.5 & 5204.1 & 70980.4 & 51397.5 & 507998.8 & 0 & 5542.6 & 9276.3 & 652490.2 \\
\hline
\end{tabular}

As shown in the Table 2, total area of land cover change in the study area reached 652490.2 square meters, amounted to $8.2 \%$ of the whole study area.

7 classes of Level I had changed within the total 9 classes. The maximum change area occurred on the class of forest land, which reached 459417.8 square meters, and most of these regions changed into structure class of Level I, amounted to $97.9 \%$ of the whole forest land area. Contrasting the pair of scenes showed that these changes were due to large reclaiming forest land for developing roads, building constructions, etc. in the study area.

The secondary maximum change area occurred on the class of artificial stack land, most of these regions changed into roads and building constructions, amounted to $46.9 \%$ and $46.2 \%$ of the whole artificial stack land area respectively. Contrasting the pair of scenes showed that these changes were due to the newly-built roads and building constructions in the study area.

\section{Conclusions}

Due to the basis of background data of land cover, the proposed method could reduce the workload of classification. Change classes could be determined only by spatial overlap analysing, which overcomes the weakness of single method either cannot extract change classes information simultaneously or relies on classification accuracy of multi-temporal images excessively.

The proposed method has combined with the national land cover database's contents and features to explore greater applicability model of change information extraction. Critical technic of 
data processing and key points of the used algorithms have been summarized and analysed, which could provide a practicable reference method for the project of geographic national conditions monitoring.

\section{Acknowledgment}

This work was supported by open fund of Key Laboratory for National Geographic Census and Monitoring, National Administration of Surveying, Mapping and Geoinformation (No.

2014NGCM08).

\section{References}

[1] D. Lu, P. Mausel, E. Brondízio, E. Moran, “Change detection techniques,” International Journal of Remote Sensing. vol. 25, pp. 2365-2407, 2004.

[2] D. R. Li, "Change Detection from Remote Sensing Images," Geomatics and Information Science of Wuhan University. vol. 28, pp. 7-12, 2003.

[3] George Xian, Collin Homer, Joyce Fry, "Updating the 2001 National Land Cover Database land cover classification to 2006 by using Landsat imagery change detection methods," Remote Sensing of Environment. vol. 113, pp. 1133-1147, 2009.

[4] John Rogan, D. M. Chen, "Remote sensing technology for mapping and monitoring land-cover and land-use change,” Progress in Planning. vol. 61, pp. 301-325, 2004.

[5] J. T. Morisette, S. Khorram, “Accuracy assessment curves for satellite-based change detection,” Photogrammetric Engineering \& Remote Sensing. vol. 66, pp. 875-880, 2000.

[6] L. Li, N. Shu, Y. Gong, "Remote Sensing Image Change Detection and Change Type Recognition Based on Spatiotemporal Relationship," Geomatics and Information Science of Wuhan University. vol. 38, pp. 533-537, 2013.

[7] Manish K Tiwari, Aruna Saxena, "Change Detection of Land Use/ Landcover Pattern in an Around Mandideep and Obedullaganj Area, Using Remote Sensing and GIS,” International Journal of Technology And Engineering System (IJTES). vol. 2, pp. 342-350, 2011.

[8] P. Rosin and E. Ioannidis, "Evaluation of global image thresholding for change detection," Pattern Recognition Letters. vol. 24, pp. 2345-2356, 2003.

[9] P. Rosin, “Thresholding for change detection,” Computer Vision and Image Understanding. vol. 86, pp. 79-95, 2002.

[10]X. F. Yu, Y. Y. Luo, D. F. Zhuang, S. K. Wang, Y. Wang, "Comparative analysis of land cover change detection in an Inner Mongolia grassland area," Acta Ecologica Sinica. vol. 34, pp. 7192-7201, 2014.

[11]Y. C. Li, J. Chen, P. Gong, T. X. Yue, "Study on Land Cover Change Detection Method Based on NDVI Time Series Datasets: Change Detection Indexes Design,” Journal of Basic Science and Engineering. vol. 13, pp. 261-275, 2005.

[12]Y. Mei, M. Lu, "Review on the Change Detection Technology Based on Remote Sensing Imagery," Geomatics World. vol. 2, pp. 42-47, 2009.

[13]Z. L. Chen, X. C. Wu, L. Wu, "Polygon Overlay Analysis Algorithm Based on Monotone Chain and STR Tree in the Simple Feature Mode," Acta Geodaetica et Cartographica Sinica. vol. 39, pp. 102-108, 2010.

[14]Z. L. Zhang, Z. Y. Zeng, S. Li, Z. F. Hu, "A Summary of Change Detection Methods of Remoter Sensing Image,” Remote Sensing Information. vol. 5, pp. 64-66, 2005. 